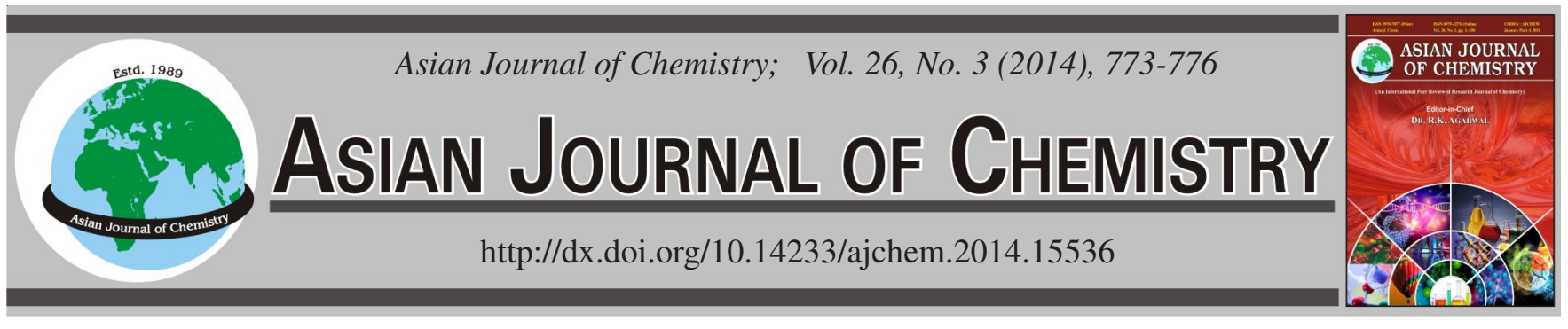

\title{
Rapid Fluorescence Polarization Immunoassay for Highly Sensitive Detection of 2,4,6-Trinitrotoluene
}

\author{
Wenzong Lu* ${ }^{*}$ Yuan Ni, Guangfeng Jia, Haixian Pan and Chen Zhao
}

Department of Biomedical Engineering, Xi'an Technological University, Xi'an 710021, Shaanxi Province, P.R. China

*Corresponding author: Tel: +86 29 86173358; E-mail: wenzonglu@126.com

\begin{abstract}
Detection of explosives is of great significance in public security programmer and environmental science. In the present work, a fluorescence polarization immunoassay based on a monoclonal antibody for the detection of 2,4,6-trinitrotoluene was established and optimized. Fluorescein-labeled (tracer) was synthesized and purified by column chromatography. The immunoassay exhibited excellent sensitivity for the detection of 2,4,6-trinitrotoluene with good stability. The detection limit was $5 \mu \mathrm{g} \mathrm{mL}^{-1}$, within a response time of 4 min. The crossreactivity of the method to 1,3,5-trinitrohexahydro-1,3,5-triazine, 2,4,6-trinitrophenol, 2,4,6-trinitrobenzoic acid, 2-nitrotoluene and 2,4dinitrotoluene, were very low (cross-reactivity $<0.01 \%$ ). The method developed is characterized by high specificity and reproducibility (coefficients of variance ranged from 2.7-6.5\% for interassay and from 1.6-4.4\% for intra-assay). The relative error value was less $1 \%$ in assay of simulating environmental sample. The fluorescence polarization immunoassay method can be applied to the screening of environmental sample for 2,4,6-trinitrotoluene without complicated operation.
\end{abstract}

Keywords: Antibody, Explosive, Fluorescence polarization immunoassay, 2,4,6-Trinitrotoluene.

\section{INTRODUCTION}

The existence of explosive nitroaromatics such as the ubiquitous 2,4,6-trinitrotoluene (TNT) at various operational and defunct military installations and munitions testing grounds throughout the world ${ }^{1}$. Monitoring the concentration of explosive materials in environmental water is important for maintaining aquatic health and eventually ensuring safe drinking water supplies as well as tracking and locating explosives materials. The environmental protection agency deems 2,4,6trinitrotoluene as toxic because it produces both toxic and mutagenic effects to the life including human, fish and microorganisms ${ }^{2}$. Consequently, several analytical methods have been developed for the detection and monitoring of explosive materials. Generally, laboratory assays for explosives have been performed using analytical instrumentation including mass spectrometric detection ${ }^{3,4}$, ion mobility spectrometry ${ }^{5,6}$, surface-enhanced Raman spectroscopy ${ }^{7}$, terahertz spectroscopy $^{8}$, X-ray ${ }^{9}$, surface plasmon resonance ${ }^{10}$, etc. Although highly sensitive and reliable, they are time-consuming, involve multiple steps in sample preparation and analysis and require expensive equipment and skilled analysts.

Nowadays, with increasing development of immunoassays, these methods have been shown to be useful alternative for analysis of explosive materials in environmental samples.
Immunosensors have also become increasingly practical tools in environmental monitoring. Recently the use of immunochemical methods has gained widespread acceptance for measuring environmental pollutants, including 2,4,6-trinitrotoluene. The Environmental Protection Agency stated the detection of 2,4,6-trinitrotoluene using antibody-based detection systems has set sensitivity and specificity criteria for investigators using this technique ${ }^{11}$. There are a variety of ways in which antibody based sensors can be configured, including methods based on ceramic matrix (sol-gel) immunoaffinity purification $^{12}$, surface plasmon resonance ${ }^{13}$, simple moleculebased fluorescent sensors ${ }^{14}$, chemiluminescent ELISA and lateral-flow immunoassay ${ }^{15}$, fluorescence resonance energy transfer ${ }^{16}$. Each technology has certain advantages and disadvantages, in regard to quantification, speed and cost; however, all are limited by either lack of sensitivity or speed for rapid detection of trace quantities of 2,4,6-trinitrotoluene.

Demands to increase speed and lower costs have lead to continued improvements in such assays. Because 2,4,6-trinitrotoluene is low molecular weight, immunoassays for its detection have generally been constructed in competitive heterogeneous formats. Fluorescence polarization immunoassay (FPIA) is a homogeneous format that does not require the separation of bound and free labels (tracer) and is getting attention as screening tool in environmental monitoring and food-safety 
control due to its simplicity, rapidity, low cost and reliability. The aim of this study was the development of a rapid, sensitive and quantitative FP immunoassay for determination of 2,4,6trinitrotoluene.

\section{EXPERIMENTAL}

Pyrenyldiazomethane (PDAM), 2-nitrotoluene, 2,4-dinitrotoluene, 2,4,6- trinitrophenol were purchased from SigmaAldrich (St Louis, MO, USA). 2,4,6-Trinitrotoluene and 1,3,5trinitrohexahydro-1,3,5-triazine were obtained from China North Chemical Industries Group Co., Ltd. (China). 2,4,6Trinitrobenzoic acid was purchased from Atomax Chemicals Co., Ltd. (China). Other chemicals used were of analytical grade. Monoclonal antibody of 2,4,6-trinitrotoluene in this study was custom in our Biomedical Engineering Lab.

Fluorescence polarization data were recorded with a Victor-2 (Perkin Elmer, USA).

Synthesis of fluorescent tracer: 2,4,6-Trinitrotoluene was conjugated to pyrenyldiazomethane according to the following procedure. $50 \mu \mathrm{g}$ 2,4,6-trinitrobenzoic acid was added to $200 \mu \mathrm{L}$ ethyl acetate solution of $0.1 \%$ pyrenyldiazomethane. The mixture was stirred for $90 \mathrm{~min}$ at room temperature. The reaction mixture was applied to the $\mathrm{C}_{18}$ solid phase extraction column using $30 \mathrm{~mL}$ methanol-water, 1:1 (v/v), as eluent. Subsequently, the column was eluted by $10 \mathrm{~mL}$ methanol and then the eluate was collected. Fractions eluting were collected from the column and the solvent was removed by a combination of vacuum evaporation and lyophilization. Finally, the fluorescent tracer was stored in methanol at $4{ }^{\circ} \mathrm{C}$.

The tracer concentrations were estimated spectrophotometrically at $492 \mathrm{~nm}$, assuming the absorbance in phosphate buffer $\left(20 \mathrm{mmol} \mathrm{L}^{-1}, \mathrm{pH}\right.$ 7.2) to be the same as for fluorescein $\left(\varepsilon=8.78 \times 10^{4} \mathrm{~mol}^{-1} \mathrm{~L} \mathrm{~cm}^{-1}\right)$. The tracer solution was further diluted in $20 \mathrm{mmol} \mathrm{L}^{-1}$ phosphate buffer and used for FPIA measurements.

Antibody titer value corresponding to the dilution of antibody which gave a $50 \%$ tracer binding was determined from the corresponding dilution curve. Working solutions of 2,4,6-trinitrotoluene monoclonal antibody was prepared by diluting aliquots of the stock solutions with phosphate buffer.

2,4,6-Trinitrotoluene standard solutions: $50 \mathrm{mg}$ 2,4,6trinitrotoluene dissolved in $3 \mathrm{~mL}$ concentrated sulfuric acid $(98.3 \%)$ and diluted with water to $1000 \mathrm{~mL}$. The concentration of standard solution of 2,4,6-trinitrotoluene was $0.05 \mathrm{mg} \mathrm{mL}^{-1}$.

Fluorescence polarization immunoassay: Antibody dilution curve was obtained by incubating 2,4,6-trinitrotoluene antibody concentrations (dilution of antiserum ranged from $1 / 50$ to $1 / 8000$ ) with an appropriate amount of fluorescent tracer $\left(2 \mathrm{nmol} \mathrm{L}^{-1}\right)$ in a total volume of $0.5 \mathrm{~mL}$ for $1 \mathrm{~min}$ at room temperature. The fluorescence polarization $(\mathrm{P})$ value was defined by the equation $P=\left(I_{v}-I_{h}\right) /\left(I_{v}+I_{h}\right)$, where $I_{v}$ and $I_{h}$ were the intensities of fluorescence of the tracer along the vertical axis and the horizontal axis, respectively, were measured for each dilution of antiserum. The polarization is commonly expressed in millipolarization units $(\mathrm{mP})$.

The competitive FPIA calibration curve was constructed with 2,4,6-trinitrotoluene at the concentrations 1, 10, 30, 100, 300 and $1000 \mu \mathrm{g} \mathrm{mL}^{-1}$. The 2,4,6-trinitrotoluene standard $(50 \mu \mathrm{L})$ was mixed with the tracer and antibody solution in phosphate buffer in a final volume of $0.5 \mathrm{~mL}$ and the $\mathrm{mP}$ signal was measured. The data were plotted against analyte concentration and a four-parameter equation was used to fit the experimental sigmoidal curve in Origin 7.0 for Windows. The assay limit of detection (LOD) was determined from the calibration curve by the blank signal and the 3 -fold confidence interval and converted into the analyte concentration. $\mathrm{IC}_{50}$ is the analyte concentration resulting in $50 \%$ inhibition of tracer binding. In these experiments to evaluate the kinetics of the competition, measurements were made after holding at room temperature for time ranging from $30 \mathrm{~s}$ and $10 \mathrm{~min}$.

Tracers working solutions were prepared by diluting aliquots of the tracer stock solutions with methanol. For each tracer, the optimum tracer concentration in the test solution was determined as the dilution of the stock solution producing a total fluorescence intensity equal to 2- to 3-fold the blank signal measured against phosphate buffer.

Cross-reactivity of the fluorescence polarization immunoassay: The cross-reactivity of the optimized FPIA was determined for structurally related (2-nitrotoluene, 2,4-dinitrotoluene, 2,4,6-trinitrobenzoic acid, 2,4,6-trinitrophenol, 1,3,5trinitrohexahydro-1,3,5-triazine). The data for anti-2,4,6trinitrotoluene was calculated according to the equation $\mathrm{CR}=$ $\mathrm{IC}_{50 \text { (TNT) }} / \mathrm{IC}_{50 \text { (cross-reactant) }} \times 100 \%$, where $\mathrm{IC}_{50}$ was the concentration of analyte or cross-reacting compound that inhibits $50 \%$ of fluorescent tracer binding.

2,4,6-Trinitrotoluene immunoassay in surface water samples: Environmental samples of surface water were spiked with 2,4,6-trinitrotoluene standard solution. The actual concentration of water samples was 10, 20, 200,500 and 1000 $\mu \mathrm{g} \mathrm{mL} \mathrm{m}^{-1}$, respectively. Fluorescent tracer $\left(2 \mathrm{nmol} \mathrm{L}{ }^{-1}\right)$ and working solutions of 2,4,6-trinitrotoluene (1/1600) were used in the assay. The mP signal of samples was measured and the measured concentration of samples was calculated by the aforementioned competitive FPIA calibration curve. Accuracy of the immunoassay was estimated by relative error values.

Statistical analysis: Statistical evaluation of data (means and standard deviations) was performed using Origin version 7.0 (OriginLab Corporation, Northampton, MA, USA).

\section{RESULTS AND DISCUSSION}

Assessment of antibody binding with fluorescent tracers: Fluorescence polarization immunoassay is a solution phase assay. Fluorescence polarization instruments indirectly measure the rate of rotation of a fluorescent molecule in solution. Because the rate of rotation is related with the size of the molecules, lager molecules rotate slower and give a higher signal than smaller molecules ${ }^{17}$. The lowest tracer concentration should be selected for a sensitive assay because FPIA is a competitive assay. For TNT-PDAM, the optimum concentration was $2 \mathrm{nmol} \mathrm{L}^{-1}$ in accordance to fluorescence intensity approximately ten times higher than the background signal from buffer.

Antibody dilution curve was recorded for assessment of antibody affinity toward the labeled antigens and antibody titer values were determined (Fig. 1). The value of the antibody titer corresponding to $50 \%$ tracer binding is dependent on tracer structure. Anti 2,4,6-trinitrotoluene showed the higher affinity toward TNT-PDAM by the titer value (1/1600). 


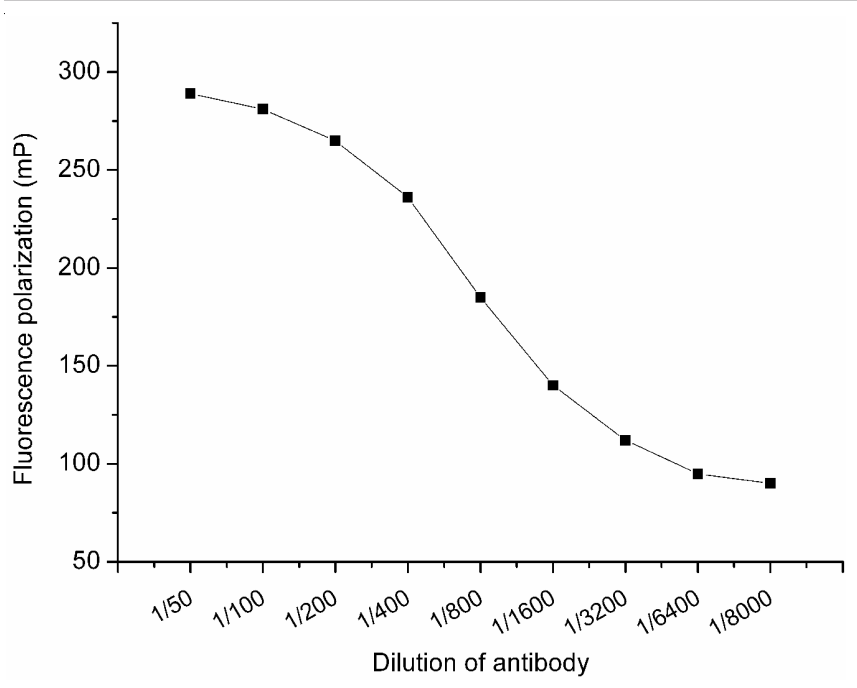

Fig. 1. 2,4,6-Trinitrotoluene antibody dilution curve of tracer

Optimization of the fluorescence polarization immunoassay: The FPIA was used to measure the competition between the tracer and unlabeled 2,4,6-trinitrotoluene in solution for binding the antibody. The effect of the antibody-tracer incubation time on fluorescence polarization response was investigated. The time required for the fluorescence polarization signal to reach equilibrium was 4 min for competitive FPIA (Fig. 2). The absence of long incubation times and washing steps reduced the time of analysis as compared to other antibody-based methods. Actually, the overall time consumed in 2,4,6-trinitrotoluene analysis with the optimized immunoassay procedure was less than $10 \mathrm{~min}$, thus allowing the performance of the analysis with a very high sample throughput.

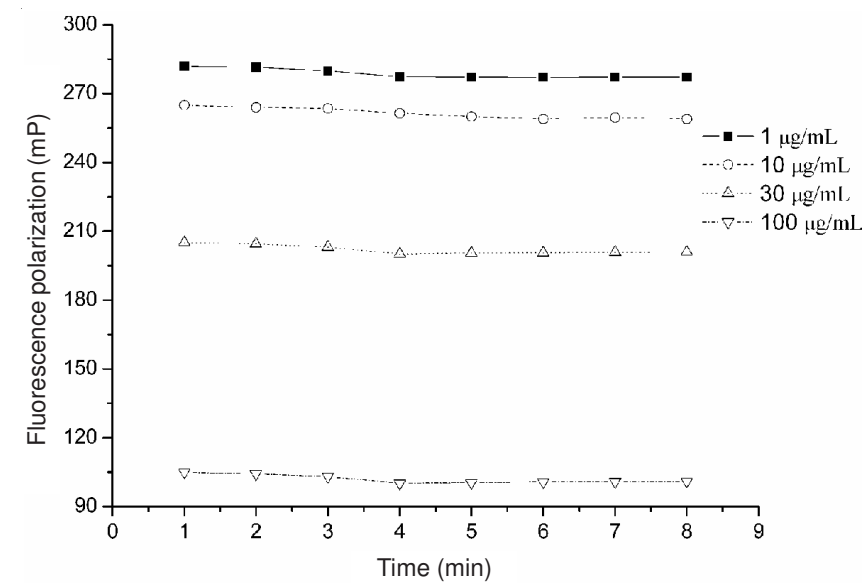

Fig. 2. Kinetics process of fluorescence polarization immunoassay for 2,4,6-trinitrotoluene
Calibration curve for 2,4,6-trinitrotoluene was obtained with different concentrations in a combination with TNTPDAM fluorescent tracer (Fig. 3). The calibration curve had an LOD of $5 \mu \mathrm{g} \mathrm{mL}^{-1}$ and $\mathrm{IC}_{50}$ above $39 \mu \mathrm{g} \mathrm{mL}^{-1}$. It should be noticed that LOD is commonly used as a measure of immunoassay sensitivity. 2,4,6-Trinitrotoluene detection using llama antibodies and a two-step competitive fluid array immunoassay and utilizing the same two-step competitive assay format the dynamic range of the monoclonal antibody was found to have a broad range $(1 \mathrm{ng} / \mathrm{mL} \text { to } 1 \mathrm{mg} / \mathrm{mL})^{18}$. The FPIA was characterized by good reproducibility; coefficients of variance $(\mathrm{CVs})$ ranged from 1.6-4.4\% within assay and from 2.7 to $6.5 \%$ between assays (Table-1).

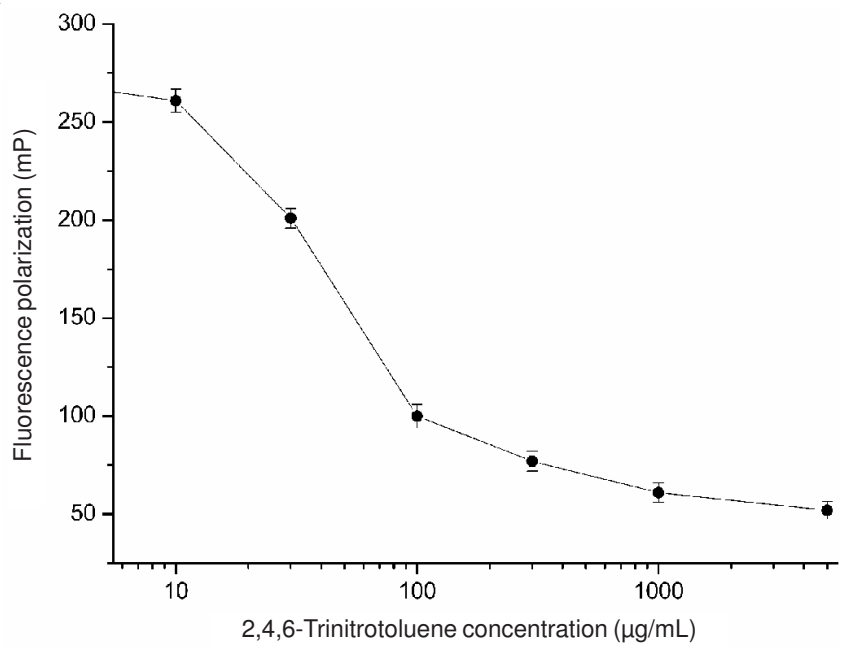

Fig. 3. Calibration curve for 2,4,6-trinitrotoluene by competitive fluorescence polarization immunoassay

Cross-reactivity of the fluorescence polarization immunoassay: To assess the specificity of developed assay, anti 2,4,6-trinitrotoluene was tested for its cross-reactivity (CR) with structurally related compounds, including 2-nitrotoluene, 2, 4-dinitrotoluene, 2,4,6-trinitrobenzoic acid, 1,3,5-trinitrohexahydro-1,3,5-triazine and 2,4,6-trinitrophenol (Table-2). A very low cross-reactivity $\left(\mathrm{CR}<0.01 \%\right.$; $\left.\mathrm{IC}_{50}>10^{5} \mu \mathrm{g} \mathrm{mL^{-1 }}\right)$ was observed for nitroaromatic compounds except for 2,4,6trinitrotoluene. The antibody demonstrated high specificity for 2,4,6-trinitrotoluene $\left(\mathrm{IC}_{50}=39 \mu \mathrm{g} \mathrm{mL} \mathrm{m}^{-1}\right)$. The antigenantibody complex formation is a complicated interaction and it is easily affected by slight differences in chemical structure. Monoclonal antibody has high specificity because it possesses highly homogenerous physico-chemical properties, single biological activity and makes only one kind of interaction with antigen epitope. Cross-reactivity is the reaction between an

TABLE-1

RSD OF INTRA-ASSAY AND INTER-ASSAY FOR FLUORESCENCE POLARIZATION IMMUNOASSAY $(\mathrm{n}=5)$

\begin{tabular}{|c|c|c|c|c|c|c|}
\hline \multirow{2}{*}{$\begin{array}{l}\text { 2,4,6-Trinitrotoluene } \\
\qquad\left(\mu \mathrm{g} \mathrm{mL}^{-1}\right)\end{array}$} & \multicolumn{3}{|c|}{ Intra-assay RSD } & \multicolumn{3}{|c|}{ Inter-assay RSD } \\
\hline & $\mathrm{FP}(\mathrm{mP})$ & $\mathrm{SD}(\mathrm{mP})$ & RSD (\%) & $\mathrm{FP}(\mathrm{mP})$ & $\mathrm{SD}(\mathrm{mP})$ & RSD (\%) \\
\hline 10 & 261 & 5.2 & 2.0 & 259 & 7.1 & 2.7 \\
\hline 30 & 201 & 3.3 & 1.6 & 203 & 6.8 & 3.3 \\
\hline 100 & 100 & 2.9 & 2.9 & 98 & 6.4 & 6.5 \\
\hline 300 & 77 & 2.6 & 3.4 & 78 & 4.7 & 6.0 \\
\hline 1000 & 61 & 2.7 & 4.4 & 62 & 4.0 & 6.5 \\
\hline Average & - & - & 2.9 & - & - & 5.0 \\
\hline
\end{tabular}


TABLE-2

CROSS-REACTIVITY OF 2,4,6-TRINITROTOLUENE ANTIBODY WITH NITROAROMATICS

\begin{tabular}{lcc}
\multicolumn{1}{c}{ Chemical } & $\begin{array}{c}\mathrm{IC}_{50}(\mu \mathrm{g} \\
\left.\mathrm{mL}^{-1}\right)\end{array}$ & $\begin{array}{c}\text { Cross- } \\
\text { reactivity }(\%)\end{array}$ \\
\hline 2,4,6-Trinitrotoluene & 39.3 & 100 \\
2-Nitrotoluene & $>10000$ & $<0.1$ \\
2,4-Dinitrotoluene & $>10000$ & $<0.1$ \\
2,4,6-Trinitrophenol & $>10000$ & $<0.1$ \\
2,4,6-Trinitrobenzoic acid & $>10000$ & $<0.1$ \\
1,3,5-Trinitrohexahydro-1,3,5-triazine & $>10000$ & $<0.1$ \\
\hline
\end{tabular}

antibody and an antigen that differs from the immunogen and is also a commonly evaluated parameter for the validation of immune and protein binding based assays such as ELISA. In this case it is normally quantified by comparing the assays response to a range of similar analytes and expressed as a percentage.

2,4,6-Trinitrotoluene immunoassay in surface water samples: To simulate environmental samples, surface water was spiked with 2,4,6-trinitrotoluene and analyzed using the optimized fluorescence polarization immunoassay. As shown in Table-3, the relative error value was less $1 \%$ at different concentration in the assay, suggesting the immunoassay was reliable and applied to environmental 2,4,6-trinitrotoluene detection.

TABLE-3

\begin{tabular}{|c|c|c|}
\hline \multicolumn{2}{|c|}{ Concentration of TNT $\left(\mu \mathrm{g} \mathrm{mL}^{-1}\right)$} & \multirow{2}{*}{ Relative error (\%) } \\
\hline Actual & Measured & \\
\hline 10 & 9.91 & 0.90 \\
\hline 20 & 19.87 & 0.65 \\
\hline 200 & 198.31 & 0.85 \\
\hline 500 & 495.79 & 0.84 \\
\hline 1000 & 991.32 & 0.87 \\
\hline
\end{tabular}

\section{Conclusion}

In this study, the FPIA method based on a monoclonal antibody for the detection of 2,4,6-trinitrotoluene was developed and optimized. The method was characterized with an
LOD value of $5 \mu \mathrm{g} \mathrm{mL}-1$ and $\mathrm{IC}_{50}$ of $39 \mu \mathrm{g} \mathrm{mL}^{-1}$. The method was highly specific and reproducible and the time of assay procedure was less than $10 \mathrm{~min}$. On the basis of these initial results, this FPIA appears to meet the 2,4,6-trinitrotoluene detection of environmental samples without complicated operation.

\section{ACKNOWLEDGEMENTS}

This work was supported by the Fund of Xi'an Technological University (XAGDXJJ1014)

\section{REFERENCES}

1. A.A. Adams, P.T. Charles, J.R. Deschamps and A.W. Kusterbeck, Anal. Chem., 83, 8411 (2011).

2. E.P. Agency, Health Advisory for TNT, Criteria and Standard Division, Office of Drinking Water, Washington, DC, USA (1989).

3. B. Balan, C. Vijayakumar, M. Tsuji, A. Saeki and S. Seki, J. Phys. Chem. B, 116, 10371 (2012).

4. F. Rowell, J. Seviour, A.Y. Lim, C.G. Elumbaring-Salazar, J. Loke and J. Ma, Forensic Sci. Int., 221, 84 (2012).

5. M. Najarro, M.E. Davila Morris, M.E. Staymates, R. Fletcher and G. Gillen, Analyst, 137, 2614 (2012).

6. M. Tabrizchi and V. Ilbeigi, J. Hazard Mater., 176, 692 (2010).

7. H. Wackerbarth, C. Salb, L. Gundrum, M. Niederkruger, K. Christou, V. Beushausen and W. Viöl, Appl. Opt., 49, 4362 (2010).

8. M.R. Leahy-Hoppa, M.J. Fitch and R. Osiander, Anal. Bioanal. Chem., 395, 247 (2009).

9. K. Wells and D.A. Bradley, Appl. Radiat. Isot., 70, 1729 (2012).

10. D.R. Shankaran, K.V. Gobi, T. Sakai, K. Matsumoto, K. Toko and N. Miura, Biosens. Bioelectron., 20, 1750 (2005).

11. E.S. Bromage, T. Lackie, M.A. Unger, J. Ye and S.L. Kaattari, Biosens. Bioelectron., 22, 2532 (2007).

12. M. Altstein, A. Bronshtein, B. Glattstein, A. Zeichner, T. Tamiri and J. Almog, Anal. Chem., 73, 2461 (2001).

13. Y. Mizuta, T. Onodera, P. Singh, K. Matsumoto, N. Miura and K. Toko, Biosens Bioelectron., 24, 191 (2008).

14. G.V. Zyryanov, M.A. Palacios and P. Anzenbacher Jr., Org. Lett., 10, 3681 (2008).

15. S. Girotti, S. Eremin, A. Montoya, M.J. Moreno, P. Caputo, M. D'Elia, L. Ripani, F.S. Romolo and E. Maiolini, Anal. Bioanal. Chem., 396, 687 (2010)

16. L. Feng, H. Li, Y. Qu and C. Lu, Chem. Commun., 48, 4633 (2012).

17. C.M. Maragos, Mycotoxin Res., 22, 96 (2006).

18. G.P. Anderson and E.R. Goldman, J. Immunol. Methods, 339, 47 (2008). 